\title{
CALLers and Learning Technologists: Where do they meet, and what do they have in common?
}

\author{
Claire McAvinia* \\ National University of Ireland Maynooth, Ireland
}

In the UK and Ireland, the context in which CALL is developing in higher education is changing. Language teachers in universities may increasingly be involved in CALL development and research, but their universities are simultaneously increasing formal central support for all staff in adopting and exploiting new technologies. In both CALL, and this wider adoption of technology, we see distinct areas of practice and research emerging. In such a context of change and growth, it is not always clear where the work of specialists in languages might dovetail with that of staff working across the institution to enhance the use of technologies for learning and teaching. In this paper, the author will examine common themes and approaches between CALL and what is often labelled 'learning technology' from a communities of practice perspective, and ask where and in what ways each can inform the development of the other.

\section{Introduction}

This paper seeks to explore aspects of the context in which new technologies are being used in higher education in the UK and Ireland. Specifically, the paper examines two areas of professional practice which have emerged around the use of new technologies. Relevant literature will be reviewed, and two brief cases from the author's experience presented, with analysis from a communities of practice perspective (Lave \& Wenger, 2002). The first area of practice mentioned, computer-assisted language learning (CALL), is clearly associated with language learning and teaching, although some authors have suggested that it draws on a number of disciplines or could be viewed as a subset of applied linguistics

*Corresponding author. Quality Promotion Office, National University of Ireland Maynooth, Maynooth, County Kildare, Republic of Ireland. Email: claire.mcavinia@nuim.ie 
(for example, Chambers, 2001; Coleman, 2005). The second area of practice arises from cross-disciplinary support for learning and teaching using new technology in higher education institutions (HEIs). It is often referred to as support in the use of 'learning technology' (LT) but may also be referred to more broadly as 'e-learning' in universities.

The issue of terminology is important in both areas, and although not the primary focus of this paper, needs some further comment here at the outset. For the purposes of this discussion, labels have been chosen as shorthand to refer to people working (predominantly) in one area or the other. 'CALLers' may be any of lecturers, teachers, developers, and researchers working with CALL in HEIs. 'Learning technologists', on the other hand, may well be a specific group of people within a HEI. However, where this is the case, it is likely to be a relatively recent development, often involving the appointment of a team to support the implementation of a virtual learning environment (VLE) such as WebCT or Moodle. ${ }^{1}$ This group is most often associated with 'supporting' the use of new technologies-computers, the Internet, software for specific subject areas, development of departmental web sites - across all subject areas in the institution. The word 'support' in this context refers not only to technical issues or training, but also to the pedagogical approaches underpinning the uses of new technology.

People working in either CALL or LT may have a wide range of responsibilities. Since their areas of work may not always be clearly defined within institutional structures, the job titles associated with these practices are not consistent either (Oliver, 2002). However, since learning technologists form the group likely to be the less familiar to readers of this journal, the nature of their work will be explored more fully in the early sections of this paper. The practices of both CALLers and learning technologists will then be examined from a communities of practice (CoP) perspective (Lave \& Wenger, 2002), with further analysis drawing on the idea of 'legitimate peripheral participation' in CoPs to examine the potential of each area to inform the other.

\section{Who are the Learning Technologists?}

Over the past two decades, we can trace a number of significant changes in universities, and indeed evolution in the roles of administrators, technical staff, library staff and others supporting academic departments in their work (Thorley, 1998). Within institutions, changes such as modularisation and semesterisation have led to the greater involvement of departmental administrators in course planning, with academics delegating more responsibility to them. One of the first and most notable references to the 'new professionals' working in higher education came in the studies undertaken for the UK's NCIHE (1997) ('Dearing'). These studies identified people working in what were then described as the 'growth areas' of higher education in the UK: student services, marketing and information services. The work of these 'new professionals' cut across administrative and academic areas, and blurred the boundaries between them. Coinciding with these emergent roles was the introduction 
of new technology to various separate central divisions of the institution, and in turn to academic departments (McAvinia \& Oliver, 2004). Later, Gornall (1999) examined the traditional classifications of staff at universities and argued that within the 'support' category, a range of new roles relating to the support of teaching and learning was identifiable. These roles were not only administrative, but could be strategic managerial, technical, or involve tutoring or training staff and students. These 'support' roles in learning and teaching, combined with support roles in the use of new technology, led to the emergence of the 'learning technologist' role we know today.

Further analysis of such new roles and activities by Beetham (2001) found a wide range of staff covering a variety of areas in their work. While the title 'learning technologists' was beginning to be used, it could refer to people working centrally but also within subject departments, in both research and development roles, and in technical support units, as well as in libraries. Beetham's (2001) study found that around 4,500 people at the centres of universities in the UK were working as learning technologists. This was exclusive of the thousands of staff in academic departments who described themselves as having some areas of work related to learning technologies.

In 2002, the existing research, as well as new data about the nature of the role, were analysed by Oliver (2002). By this time it was possible to talk about the learning technologist's work in terms of a more specific job description. Although the role now seemed to have particular forms of collaboration with academic staff at its core, it could nonetheless include a range of other responsibilities including teaching, administrative duties, research and technical services (Oliver, 2002). Different studies have emphasised different aspects of the work, demonstrating its fluidity: Surry and Robinson (2001), who developed a taxonomy of LT roles, focused on service positions rather than academic ones. Although Oliver (2002) comments that there is little data on the emergence and development of this role outside the UK (with the exception of Surry and Robinson's 2001 study in the USA), it does now seem to have gained currency in a number of countries, based on the evidence from job advertisements and new or refined university structures. The terms 'learning technology' and 'learning technologist', although potentially unclear (and contested even within the field) appear to be known and recognisable in the UK, Ireland, the US, Australia and New Zealand. ${ }^{2}$

\section{LT and CALL as Communities of Practice}

From the description of the emerging role of learning technologists given above, and the identification of areas of work in which they are engaged, we can suggest that they represent a community of practice (CoP) within higher education. The CoP model offers a useful lens through which to view both LT and CALL, and indeed it has been used as such in a number of research studies (e.g., Oliver, 2002). While space prevents a full description or discussion of CoP here, it is important to revisit its key aspects. The model is based on the idea that all human activity is inherently social, and that learning takes place within a community of practitioners (Lave \& Wenger, 
2002). The idea of a 'community of practice' as described by Lave and Wenger entails a social grouping with its own sets of meanings and processes. Members of the community participate in its social relations, and its activities, and engage with the technologies of normal practice in that community. The group may have newcomers as well as existing members, and newcomers are comparable to apprentices who learn how to interact with other members of the community and to express themselves in its terms.

This model is helpful in framing and beginning to analyse the work of particular groups, but has perhaps greater usefulness as a heuristic for the interaction between communities. Lave and Wenger's idea of 'legitimate peripheral participation' (2002) proposes a form of apprenticeship by which a newcomer engages with a community. This is defined in terms of 'situated learning' within a particular context and through particular activities. Legitimate peripheral participation sees newcomers perform some of the non-critical activities of the community, develop awareness of social relations (and power relationships) within the community, and learn about the degree to which different members have access to community resources.

Bound into the CoP model are ideas of how technology is used by the community. 'Technology' here is taken to include all media (not only new media), tools, and can include language. Tools are important because one aspect of the definition of the community is in terms of the tools it uses. Importantly, Lave and Wenger (2002) suggest that membership of multiple overlapping communities is also possible. Contributions to each CoP from particular individuals may therefore vary from time to time.

In CALL and LT, then, we have two distinct communities: each has evolved from the use of a range of new technologies to enhance learning and teaching activities. Each has agreed social practices surrounding these activities. But what distinguishes one group from the other, and how do they interact when they do meet? Is there legitimate peripheral participation between one community and the other? These questions will be considered in the next sections.

\section{CALLers and Learning Technologists: Where do they meet?}

\section{Collaboration: Face-to-face}

Since the role of the learning technologist is to meet with academic staff in departments, and to provide pedagogical and technical support to them, this presents one obvious mechanism by which they might meet CALL practitioners. Where development work ensues from such meetings, it is very often framed as a project, in order to manage limited time (and any available financial resources). Projects may be very informal or consultative in nature, but they may also lead to what Oliver describes as 'collaborative curriculum development, usually initiated by an academic and focused on a particular piece of technology' (2002, p. 251). This kind of involvement in the work of a specialist in a subject area can be characterised somewhat differently to conventional training or technical support. Two brief 
examples from the author's experience in a learning technologist role will now be presented to illustrate this.

Case 1: Virtual Departments for Minority Languages (VDML). ${ }^{3}$ This project ran from 2000-2002 and was to link three Danish language departments in the UK via a VLE (WebCT). Teachers learned to develop and publish webpages and multimedia files for use within the VLE. Students communicated with each other using the technology, and some collaborative activities in the target language took place between them (Roed, 2003). In addition, teachers could re-use and adapt each other's resources where they felt this was appropriate to their needs. Throughout, they were supported by a team which included researchers and learning technologists.

The language tutors coming to this project had no experience of web authoring, although they were confident about finding suitable web-based resources in Danish for their students. Collaboration between the team and the teachers, particularly in the earliest phases of the project, was intensive. Decision-making around the system to be used, as well as the kinds of resources the teachers wished to make, were priorities. Teachers talked to the learning technologists about their pedagogical decision-making. Technical training was provided, as was ongoing support via email, telephone, and on an individual, face-to-face basis. The project at each stage relied upon this collaborative activity, which carried through to the work undertaken between the teachers, and later, between their students. Thus, the project resulted in the creation of resources for teachers and students to use via a VLE. However, it also developed ways of working collaboratively, which were extended to participating tutors' teaching practices during and after the project. ${ }^{4}$

Case 2: A Taste of Languages at School (ATLAS). ${ }^{5}$ In this project, small web sites were designed and published to give school students a 'taster' course in each of Czech, Danish, Portuguese, Polish and Russian. This was to encourage them to apply to study a language at university, and was in response to the falling numbers of students applying to language courses in the UK. The project was also a way of reminding students that they could begin a language ab initio at university. The author's role was as 'technical developer' to the project team.

While the project was not conceived primarily as a form of professional development for the teachers involved, it nonetheless had that potential. Collaboration with the technical developer was implicit, to a greater or lesser extent. Indeed, two of the five teachers became heavily involved in the process of developing the web sites for their languages. One of these teachers was a CALL practitioner, who had previous experience developing web-based materials and using a VLE with her students. In her case, the collaboration could begin with an existing awareness of the potential of the web for supporting language learning, as well as her existing technical knowledge. The technical developer's role changed to resemble more closely the collaborative learning technologist role. The resulting site was the richer for this different relationship. However, in the case of three of the teachers, the necessary focus on the production of the resources within a short timescale affected their 
engagement considerably. They had no previous experience in developing materials for the web, and produced paper-based texts for 'transfer' to webpages without envisaging the need for any adaptation or further discussion with the technical developer.

The taster web sites were well received, and the resources were successfully adopted within targeted schools (King, Hughes, \& McAvinia, 2004), but they were somewhat uneven in terms of amounts of content and technical sophistication. As a small-scale initiative, the project did not have much scope for sustained collaborative developmental activities with the language teachers, nor did it have resources to conduct research into the teachers' experiences at its conclusion. However it seemed that, at least in terms of the author's experience, the disengagement of some of the teachers could have been linked to a lack of any existing CALL experience and the lack of designated space for their professional development within the project.

These examples are typical of the kinds of projects undertaken by learning technologists in HEIs, and of the kinds of challenges encountered. The teachers in Case 1 were engaged with CALL by the end of the project. One of the teachers in Case 2 was already using CALL, and developed her skills further within the project. Another teacher developed a keen interest in the area and subsequently could have been labelled a 'CALLer'. These examples show interactions between LT and languages, and in the case of the 'CALLers', an interaction between LT and CALL. Although merely descriptive examples, they show that a more productive collaboration resulted between the CALLers and the author in Case 2. The possible implications of this will be analysed later.

\section{Encounters in Research}

A second area in which learning technologists and CALLers meet is research. There are significant bodies of research in both LT and CALL, and examples of crossover and indeed synergy between the two. Both fields are concerned with documenting work, but also with reflection on the evolution of the respective areas. Both seek to develop appropriate pedagogical and theoretical models, as well as suitable research methodologies. Both have focused on the changing role of the teacher in the digital age.

Researchers in CALL and LT alike frequently address the nature of their 'subjects' and indeed the fitness of these subjects for research. They describe similar experiences in the development of LT and CALL as research areas (or even, arguably, as disciplines). These similarities are perhaps most striking in relation to accounts of the period 1993-2003. 2003 saw the tenth anniversary conferences of ALT (the UK's Association for Learning Technology), and EuroCALL (the European Association for Computer Assisted Language Learning). Seale (2003) retraces the steps that led to the foundation of ALT, an organisation which has now gained momentum to the extent that it can map out a research agenda for LT (Conole, 2003), and has co-funded work to develop a professional accreditation framework for LT staff. ${ }^{6}$ Davies $(1997,2001)$ enacts the same kind of historical 
retracing of footsteps in the development of CALL and EuroCALL, and in turn asks whether CALL is a suitable field for research. Beatty (2003) produced a textbook-like guide to new researchers in CALL, suggesting an anticipated growth in this work. CALL and LT papers argue their cases for the establishment of both as disciplines. However, the issue of disciplinarity appears unresolved in both CALL (Coleman, 2005) and LT (Oliver \& Dempster, 2003), where the matter is complicated by the apparent lack of a foundation discipline.

Aside from these existential concerns, links between LT and CALL are evident even from a glance at the literature. Leading writers in LT can be found prefacing CALL research (Laurillard, 2003) and prominent researchers in CALL present their work to the LT audience (for example, Felix, 2003). In the work of Goodfellow (2003) amongst others, we find a pattern of publication in both areas over a number of years. One factor accounting for these writers' ability to cross between both fields is a shared interest in constructivism in learning and teaching. This is perhaps unsurprising since both LT and CALL focus on the development of innovative practice in education. However, there are nuances within the various interpretations of constructivism by researchers and practitioners in each area.

One aspect of this discussion in both LT and CALL has been the changing role of the teacher/tutor. New technologies are frequently associated with a diminished role for the teacher, either on economic grounds (financial savings by an educational institution) or on bona fide educational grounds (a change in pedagogical approach towards a student-centred environment). Although we see the role of the teacher changing in CALL and LT research, and the notion of control very much changed, the teacher is by no means absent. Instead, responsibilities are redefined. Laurillard (1993) asserts the role of the teacher very strongly: the teacher is responsible for providing the opportunities for learners to realise what they do and do not know. In CALL, recent attention to learner autonomy similarly asserts the teacher's responsibilities in helping learners to take responsibility for their own learning (Little, 1995).

The idea of dialogue, and social constructivism, is important to both CALLers and learning technologists. Laurillard's 1993 book, Rethinking university teaching, is frequently cited in LT research. It centres on the idea of the 'conversational framework' and is indeed renamed accordingly in its second edition (Laurillard, 1993, 2001). CALL, in its treatment of constructivist approaches, similarly concentrates on the importance of dialogue, but for different reasons, since dialogue is also a function of using the target language. Different kinds of dialogue are important in CALL. Conversation may be happening in one or more languages, or it may be a dialogue internal to the learner from the perspective of learner autonomy (Little, 1995). Therefore, theoretical approaches may be shared in LT and CALL, but they may not be addressed in the same ways. However, what CALL and LT may have in common here is a struggle to encourage more consistent engagements with theory. Researchers make regular pleas for this, fearing a 'namechecking' or superficial approach to theory. In LT research, social constructivism can tend to be construed as simply providing learners with any kind of technical facility for 
communication. Similarly, CALL researchers frequently revisit the nature and characteristics of learner autonomy to discourage interpretations of autonomy as independent (or simply solitary) learning.

There is evidence that other theoretical approaches prominent in one area might usefully be developed further within the other. One recent example is that of activity theory (AT) (Issroff \& Scanlon, 2002). AT frames human activity in units for analysis according to individuals, their objectives, the tools they use, and the mediating influences of community, rules and division of labour. Although this theory has been discussed in CALL research in the past, a recent paper by Blin (2004) offered the most similar treatment of the theory in a CALL context to that seen in LT research. Blin's concluding remarks advocate further engagement with and development of the theory within CALL.

Researchers in both CALL and LT, then, have produced a body of work that documents the development of their practice over time. This work indicates realistically the kinds of challenges brought by computer-based, and particularly web-based, learning. It has redefined and reasserted the role of the teacher in this changing environment. There are shared understandings informing and developing both areas, and evidence from one has the potential to corroborate experience in the other.

\section{Legitimate Peripheral Participation?}

The preceding sections have shown the existing but rather 'organic' links between areas of research and practice for CALLers and learning technologists. A more meaningful analysis might view this as legitimate peripheral participation by members of one community in the work of another. In Oliver's (2002) treatment of the CoP model, the communities of LT and the subject department are described as being brought into contact. There is legitimate peripheral participation by the learning technologist in the subject department, and by the collaborating academic in the practices of the learning technologist. This process involves the sharing of tools/technologies, terminology, the 'language' of the discipline, and other practices in both fields. This is a two-way process leading to learning for participants in both communities.

Revisiting the earlier examples, we can see the usefulness of this perspective. In Case 1 above, legitimate peripheral participation is evident for both groups. The project team, functioning in learning technologist roles, participated in the language teachers' community: in their social relations, their activities, and the technologies of normal practice in that community (for example, existing textbooks and paper-based resources). The language teachers had a reciprocal experience in relation to LT, and in fact one of them has since moved to a post as a learning technologist in another institution. There were clear learnings for each group.

In Case 2, it is clear that some of the teachers did not participate in the LT community, nor could the technical developer participate in their CoP. The project had not been designed explicitly to develop this kind of reciprocal participation, but without it there seemed to be disengagement by some of the teachers. In spite of this, 
the existing experience of the CALL practitioner allowed for a rich collaboration with the technical developer. In this case, the CoP model could have been used to enhance the project design at the outset, and one potential consequence of this might have been full participation by the disengaged teachers. However, in the case of the existing CALLer, the participation was more than 'peripheral'.

In research too, there is potentially more than a 'peripheral' sharing of practices between LT and CALL. The ability of researchers to write in both areas perhaps proves that multiple and overlapping memberships of different communities are indeed possible. This is evident in social practices surrounding research too: CALLers and learning technologists attend each other's conferences and contribute to each other's email lists.

There is then evidence of shared practices, but also shared technologies. This is in terms of computer-based technologies, but also in terms of theoretical approaches and terminology as the tools of academic CoPs. This prompts the question whether, rather than framing these common areas in terms of 'legitimate peripheral participation', we should ask instead if a new community, or even a new discipline is being formed. The 'peripheral' areas are already shared and understood by practitioners and researchers in both communities. Why then should CALLers and learning technologists not be viewed as one community?

One response to this question might be to point out that both areas nonetheless retain important differences, for example, in respect of research methodologies. Researchers in both areas use both quantitative and qualitative methods in their work. However, they struggle in various ways with the potential methodological problems inherent in this (Beatty, 2003; Oliver \& Conole, 2003). The response in LT research has been to develop alternative methods of evaluating the impact of new technologies on learning and teaching. Specific funding has been allocated in the UK to a number of high profile projects addressing evaluation methods. Documentation and indeed 'toolkits' arising from these projects are freely available for others in the sector to use (for example, the Evaluation cookbook at www.icbl.hw.ac.uk/ltdi/cookbook/). These add considerably to the range of tools learning technologists can use in their work, and differentiate their community from that of CALL.

This is one indication that we are not witnessing the emergence of a new LT/CALL discipline, at least not in the terms discussed by Rumble (1998). Instead, it may be more appropriate to consider instead the extension or reconfiguration of the CoP model to accommodate a view of reciprocal participation between communities beyond the 'peripheral' level. In suggesting this, there is an implicit question about the extent of a learning technologist's involvement in any one subject area. The CoP model is most useful in characterising the 'peripheral' participation a learning technologist might have in many other communities (Oliver, 2002). Can there be sustained engagement with a subject if learning technologists' work is based on initial contact and development work with staff? Is there 'another' level, as the interaction between CALL and LT seems to show, or is that the point at which subject specialists (in any area of work) become confident to work alone with new technologies, and should be left to do so? 
Some of the preceding argument has suggested that this other level of engagement and collaboration between CALLers and learning technologists, even if at present undefined and 'organic', should be sustained. Indeed, characterising more precisely the nature of this 'level' could have important implications for the development of practice in LT and in CALL. There are pragmatic reasons for this: both groups can share information and experience not only with existing technologies, but with new technologies as they come into use. The dissemination of good practice in CALL may have much to offer to other subjects, and this could be done via LT research journals and conferences, or even within institutions and their own particular structures. Learning technologists are usually keen to meet with early adopters or 'champions' in different subject areas (Oliver \& Dempster, 2003). These 'friendly academics' may have experiences to disseminate across the institution which encourage others to consider using new technologies.

This discussion suggests a collaborative, reciprocal participation that is of a qualitatively different nature to the traditional interactions between 'content specialists' (in this case, language teachers) and 'instructional designers' (in this case, learning technologists). Love (2002) addresses the tensions that can exist in these relationships, exploring the educational design of a CD-ROM for pre-service schoolteachers. Similarly, Sinclair, Aldred and Smith (2002) describe and discuss the relationship between content experts and instructional designers of a CD-ROM for English language teaching. Both papers foreground the potential misunderstandings in these relationships, and indeed discuss the weakening of boundaries between each group as work progresses (Sinclair et al., 2002). Learning technologists are not instructional designers: on the one hand, this means that they are not usually contracted to meet a design brief. On the other hand, they can engage with a subject from the perspective of continuing professional development for the subject specialist with whom they are working, and a deeper engagement with that subject may result.

The nature of this qualitative difference is well articulated by Jones (2004), who comments on the learning technologist's involvement with research and practice in the disciplines. This differentiates the role from that of instructional designer, graphic designer or technical support person. Learning technologists are, at least at the moment, afforded the opportunity to participate in other disciplines, and to carry out research into their own activities. Jones (2004) treats this as a strength of their work, but also as a confounding characteristic that could well obstruct the professionalisation of the work, or even disappear with that professionalisation:

Learning technologists have diverse origins and their work involves the coordination of a wide variety of feeder disciplines. Learning technologists are as a result faced with having to have an appreciation of broad theoretical questions in order to understand the diversity of approaches available in the field. (Jones, 2004, p. 1)

Jones indicates that learning technologists are well accustomed to participating in many communities of practice by virtue of their work, but also owing to the range of 'feeder disciplines' to the field. He concludes, however, that they must begin to agree on what counts as theory and knowledge in their field of work. 


\section{Change in Higher Education and the Formalising of LT and CALL}

The notion of new fields of theory and knowledge arising from the work of CALLers and learning technologists suggests a further area in which they are encountering each other, and indeed are likely to continue to meet in the future: change in higher education itself, and the formalisation of working practices in CALL and LT. The rationale for this paper is not simply to share information about the different groups working with technologies in learning and teaching in HEIs, nor to describe links between the two. Rather, it is to consider the ways in which wider changes in HEIs may impact on each. This section will consider these changes in more depth.

CALL has traditionally been an experimental, 'voluntary' activity for people working in languages. While many language teachers in HEIs have been developing their practice in the use of computers for language teaching and learning for at least the past two decades (Davies, 1997, 2001), and there are histories of CALL charting its development alongside that of the personal computer (for example, Beatty, 2003), there are many who have not yet come to exploit this new technology (Schwienhorst, 1999). The same has been true in other subject areas: the potential use of computers in teaching and learning has depended in part on the subject area, and in part on the extent of individual academics' personal interest. This 'organic' activity has not existed in the absence of policy from government - at least, not in the UK. Smith (2005) traces a 40-year long history of policy in relation to e-learning in Britain. However, the Internet appears to have been the catalyst for far-reaching change, and signs of this change are now apparent (Lea $\&$ Nicoll, 2002). Institutions have begun to formalise their approaches to the use of technology in teaching and learning. This is mirrored even in the technical systems themselves, historically 'standalone', but increasingly being joined partially via VLEs or wholly via the concept of the 'managed learning environment' (MLE) (Smith, 2005). These changes are not designed exclusively to improve administrative efficiency within the institution, nor are they related solely to the improvement of the teaching and learning environment. They are motivated by ambitious longer-term plans: flexible, globalised course delivery (Nunan, 2000).

The implication of this change is that academics or researchers working in specific subject disciplines, who may previously have regarded their use of computers in teaching as experimental for their part, or optional for the part of their students, now find that their institutions have a strategic interest in their work. Internet and mobile technologies signal potential 'markets' for institutions, including students at home and abroad (in particular, those in the 'overseas' categories outside the European Union). The HEIs are in turn taking their cues from national strategies. Universities in the UK have external drivers from the Department for Education and Skills' e-learning strategy (DfES, 2005), as well as strategies prepared by funding councils and agencies (most recently, HEFCE, 2005). These changes are well documented elsewhere, and indeed have been treated specifically in relation to CALL (Coleman, 2005) and LT (Clegg \& Steel, 2002; Oliver \& Dempster, 2003).

Both CALLers and learning technologists find themselves bound up in these processes of change, but are also in a position to question them. Oliver and Dempster 
(2003) focus closely on this predicament: learning technologists can often have a high level of influence and control over institutional strategies and the systems selected for their institutions. However, this is counterbalanced by the demands of other institutional pressures, if e-learning is viewed by the institution as a means to 'sell' to a global market (Oliver \& Dempster, 2003). Oliver's (2002) study revealed that learning technologists were focused on the development of close collaborative relationships with colleagues across their institutions. They felt that their work was 'value-led rather than technology-led' (Oliver, 2002, p. 249) and had a pedagogic focus. Working together with 'CALLers', who may be more likely to be located in academic or otherwise more recognisable positions in academic departments, could help to defend these values in the face of institutional demands.

CALL, and indeed the wider use of technology in different subject areas, is facing increasing pressure to conform to institutional strategies and meet institutional goals. While systems and supports are being provided to help academics in departments, there may also be institutional demands around the use of LT, to serve the discourse of flexibility (Clegg \& Steel, 2002) and the drive to recruit students. While learning technologists are very well aware of the pragmatic agendas their institutions may have, they argue for their own work to be pedagogically driven. Collaboration with CALLers in the interests of pedagogically sound practice might arguably be the strongest kind of 'meeting' the two groups could have. However, such a political (or even philosophical) allegiance might well have its origins in smaller-scale project work and collaborative research activities - the kinds of activities in which they are already engaged.

\section{Conclusions}

This paper has reviewed actual and/or potential meeting points between people working in LT and CALL in HEIs. A CoP-informed view of the legitimate peripheral participation between expert learning technologist and expert subject specialist still holds true in terms of development projects with language teachers new to computerbased and web-based technologies. However, this model may need to be extended or modified in light of the interaction between CALLers and learning technologists, which appears to be of a different order of sophistication, and which moves the work on from the more traditional focus on 'content expert' meeting 'technical expert'. Moreover, there are arguably significant gains to be made from actively encouraging links in research and practice, and in seeking to characterise and describe interactions between the communities beyond the 'peripheral' level.

Both CALLers and learning technologists have experience with which to inform their institutions (and colleagues in other subjects) about the nature of their work, its challenges and rewards. In terms of research, both areas are developing appropriate research methodologies, adapting and extending appropriate theoretical and pedagogical models in order to inform their work, and ensuring that these are understood within their own communities. There are themes and areas of research in common, with writers in both fields documenting their experiences and showing 
evidence for new methods and the benefits they can bring (Felix, 2003). Importantly, researchers in both areas are concerned with the nuances of different subjects: in CALL, because the research is based within existing established subjects, and in LT because both research and development work hinge on good collaborative relationships with colleagues in a variety of subject departments. Dialogue is present between the two areas, as the preceding discussion has shown, and it may now be a question of acknowledging and further encouraging this dialogue amongst practitioners in the interests of both areas.

A potential strength of the growing dialogue between researchers and practitioners in CALL and LT is that they can present a stronger overall argument in favour of pedagogically-driven approaches to the use of new technology for learning and teaching in HEIs. If universities, and other policy-makers, can look around and find evidence of the effectiveness of such approaches in more than one place, it will reinforce the argument to proceed in this way. Furthermore, the strength of two 'voices' in the university, each advocating in well-argued and research-informed terms the value of a pedagogically driven approach to the use of new technologies may help to mitigate the effects of the wider pressure of market forces.

\section{Notes}

1. http://www.webct.com, http://www.moodle.org/.

2. For example, http://www.tcd.ie/CAPSL/clt/index.php; http://www.ilta.net; http://www.alt.ac.uk/; http://is-alt.massey.ac.nz/; http://teaching.lse.ac.uk/tech/.

3. http://www.ucl.ac.uk/calt/vdml/.

4. Two of the teachers continued to collaborate in the development of their learning materials. When one of them left her institution, her replacement continued to collaborate with the second teacher until he too left his institution.

5. http://www.ucl.ac.uk/atlas/.

6. http://www.alt.ac.uk/cmalt.html.

\section{References}

Beatty, K. (2003). Teaching and researching computer-assisted language learning. London: Pearson Education.

Beetham, H. (2001). Career development of learning technology staff: Scoping study. Retrieved on February 13, 2006, from http://www.jisc.ac.uk/index.cfm?name=project_career

Blin, F. (2005). CALL and the development of learner autonomy: Towards an activity-theoretical perspective. ReCALL, 16(2), 377-395.

Chambers, A. (2001). Introduction. In A. Chambers, \& G. Davies (Eds.), ICT in language learning: A European perspective (pp. 7-12) Lisse: Swets \& Zeitlinger.

Clegg, S., \& Steel, J. (2002). Flexibility as myth? New technologies and post-fordism in higher education. Proceedings of the Networked Learning Conference, Universities of Lancaster and Sheffield.

Coleman, J. (2005). CALL from the margins: Effective dissemination of CALL research and good practices. ReCALL, 17(1), 18-31.

Conole, G. (2003). Understanding enthusiasm and implementation: E-learning research questions and methodological issues. In J. K. Seale (Ed.), Learning technology in transition: From Individual enthusiasm to institutional implementation (pp. 129-146). Lisse: Swets \& Zeitlinger. 
Davies, G. (1997). Lessons from the past, lessons for the future: 20 years of CALL. In A.-K. Korsvold, \& B. Rüschoff (Eds.), New technologies in language learning and teaching. Strasbourg: Council of Europe.Retrieved February 13, 2006, from http://www.camsoftpartners. co.uk/coegdd1.htm

Davies, G. (2001). New technologies and language learning: A suitable subject for research? In A. Chambers, \& G. Davies (Eds.), ICT in language learning: A European perspective (pp. 13-27). Lisse: Swets \& Zeitlinger.

DfES. (2005). Harnessing technology: Transforming learning and children's services. Retrieved February 13, 2006, from http://www.successforall.gov.uk/index.cfm?pg=143

Felix, U. (2003). Teaching languages online: Deconstructing the myths. Australian fournal of Educational Technology, 19(1), 118-138.

Goodfellow, R. (2003). Literacies, technologies and learning communication-speaking and writing in the virtual classroom. Keynote speech EUROCALL 2003, University of Limerick.

Gornall, L. (1999). 'New professionals': change and occupational roles in higher education. Perspectives, 3(2), 44-49.

HEFCE. (2005). HEFCE strategy for e-learning. Higher Education Funding Council for England, Joint Information Systems Committee, Higher Education Academy. Retrieved August 10, 2005, from http://www.hefce.ac.uk/pubs/hefce/2005/05_12//

Issroff, K., \& Scanlon, E. (2002). Using technology in higher education: An activity theory perspective. Fournal of Computer Assisted Learning, 18, 77-83.

Jones, C. (2004) Theory and Practices of Learning Technology. Retrieved February 13, 2006, from http://www.shef.ac.uk/nlc2004/

King, T., Hughes, J., \& McAvinia, C. (2004) Arousing an interest in school students for the take up of "new" languages at university; the ATLAS project. Proceedings of Navigating the New Landscape for Language Conference, National Centre for Languages (CILT), London 2004. Retrieved February 13, 2006, from http://www.lang.ltsn.ac.uk/navlang/papers.html

Laurillard, D. (1993). Rethinking university teaching: A framework for the effective use of educational technology. London: Routledge.

Laurillard, D. (2001). Rethinking university teaching: A conversational framework for the effective use of educational technology. London: RoutledgeFalmer.

Laurillard, D. (2003). Foreword. In U. Felix (Ed.), Language learning online: Towards best practice (pp. ix-x). Lisse: Swets \& Zeitlinger.

Lave, J., \& Wenger, E. (2002) Legitimate peripheral participation in communities of practice. In M. Lea, \& K. Nicoll (Eds.), Distributed learning: Social and cultural approaches to practice (pp. 56-63). London: RoutledgeFalmer.

Lea, M., \& Nicoll, K. (2002). Editors' introduction. In M. Lea, \& K. Nicoll (Eds.) Distributed learning: Social and cultural approaches to practice (pp. 1-15). London: RoutledgeFalmer.

Little, D. (1995). Learning as dialogue: The dependence of learner autonomy on teacher autonomy. System, 23(2), 175-181.

Love, K. (2002). Scaffolding as a metaphor in disciplinary content and in multimedia architecture: A CD-ROM on Building Understandings in Literacy and Teaching. Australian fournal of Educational Technology, 18(3), 377-393.

McAvinia, C., \& Oliver, M. (2004). Developing a managed learning environment using roundtables: An activity theoretic perspective. Interactive Learning Environments, 12(3), 209-225.

National Committee of Inquiry into Higher Education. (NCIHE). (1997). Higher education in the learning society. Norwich: Crown Copyright.

Nunan, T. (2000). Exploring the concept of flexibility. In V. Jakupec, \& J. Garrick (Eds.), Flexible learning, human resource and organisational development (pp. 47-66). London: Routledge.

Oliver, M. (2002). What do learning technologists do? Innovations in Education and Training International, 39(4), $1-8$.

Oliver, M., \& Conole, G. (2003). Evidence-based practice and e-learning in higher education: Can we and should we? Research Papers in Education, 18(4), 383-395. 
Oliver, M., \& Dempster, J. (2003). Embedding e-learning practices. In R. Blackwell, \& P. Blackmore (Eds.), Towards strategic staff development (pp. 142-153). Buckinghamshire: OUP.

Roed, J. (2003). Language learner behaviour in a virtual environment. Computer Assisted Language Learning, 16(2/3), $155-172$.

Rumble, G. (1988). Animadversions upon the concept of distance education as a discipline. fournal of Distance Education, 3(1). Retrieved June 12, 2005, from http://acde.icaap.org/vol3.1/ rumble.html

Schwienhorst, K. (1999). Teacher autonomy in multiple-user domains: Supporting language teaching in collaborative virtual environments. Fournal of Information Technology for Teacher Education, 8(2), 199-214.

Seale, J. (2003). Enthusiastic implementation: Setting the scene for evolution and revolution. In J. K. Seale (Ed.), Learning technology in transition: From individual enthusiasm to institutional implementation. Lisse: Swets \& Zeitlinger.

Sinclair, M., Aldred, S., \& Smith, R. (2002). Facilitating the collaborative design of flexible learning materials: Investigating the synthesis of content and multimedia knowledge and expertise. Australian fournal of Educational Technology, 18(3), 293-307.

Smith, J. (2005). From flowers to palms: 40 years of policy for online learning. Association for Learning Technology fournal (ALT-7), 13(2), 93-108.

Surry, D. W., \& Robinson, M. A. (2001). A taxonomy of instructional technology service positions in higher education. Innovations in Education and Teaching International, 38(3), 231-238.

Thorley, H. (Ed.). (1998). Take a minute: Reflections on modern higher education administration. Lancaster: Unit for Innovation in Higher Education. 